\section{A importância do personagem na adaptação liferá- ria de Agosto}

\section{RESUMO}

Este trabalho busca levantar um aspecto um tanto discutido entre comunicólogos e acadêmicos, ligados à literatura: 0 uso de clássicos literários para a realização de programas televisivos, incluindo telenovelas, minisséries, especiais e filmes.

\section{ABSTRACT}

This text deals with a subject frequently discussed about among communication researchers and literary critics: the adaptation of classic works of literature for tv programs, be they soap operas, serials, specials or films.

\section{Paula Regina Puhl}

Mestranda

Programa de Pós-Grad.- FAMECOS/PUCRS
IREMOS NOS APEGAR somente no que envolve as miniséries, especificamente, a minisérie Agosto veiculada pela Rede Globo de Televisão em 1993, baseada na obra literária do mesmo nome, escrita por Rubem Fonseca.

Além de levantar aspectos sobre adaptações literárias, a fusão do romance e televisão, faremos uma análise de dois personagens, que pertencem à mesma cena, que possui diálogos semelhantes tanto na minisséire quanto no romance.

$\mathrm{O}$ motivo pelo qual estabeleceu-se estudar os personagens pode ser justificado pelo fato de que personagem é a ação, seja em um romance ou em um programa televisivo, pois como define Field (1979), o personagem é o responsável pelos diálogos, além da história girar em torno dele.

A palavra personagem deriva de persona, a máscara do teatro romano (Schüler, 1989), e é esta máscara que esconde o caráter esquivo das personagens, que definem bem a fantasia que povoa o mundo romanesco.

Rey acredita que o personagem é o grande elo entre o autor e o público. "Se bem concebido, por inteiro, pode salvar uma história fraca ou até dispensá-la; pois traz, no bojo, toda uma bibliografia repleta de fatos", acrescenta o romancista e roteirista de televisão Marcos Rey (1989: 27).

Shakespeare é um exemplo disso, suas peças teatrais talvez fossem criadas a partir do personagem: Hamlet, Otelo, Romeu e Julieta, Macbeth. Na nossa literatura, o leque é ainda maior: Macunaíma, a Moreninha, Teresa Batista, entre outros...

Então, este ensaio tentará analisar este elemento tão importante para o sucesso de 
uma história - o personagem.

Porém anteriormente teremos um caminho a seguir, onde mostraremos instâncias importantes, para a compreensão da nossa análise final.

\section{A financiadora de superprodu- ções: Rede Globo}

Este breve perfil da Rede Globo de Televisão serve para conhecermos um pouco a empresa de comunicação que possui o maior Ibope entre os brasileiros, além de ser a responsável pela veiculação da adaptação literária em estudo.

A Rede Globo, então apenas o Canal 4 do Rio de Janeiro entrava no ar no dia 26 de abril de 1965, às 11 horas. Seu fundador foi o jornalista Roberto Marinho. Ao longo de mais de 30 anos de funcionamento, transformou-se em rede nacional.

Destacando-se em um mercado televisivo essencialmente amador, flagrante na data de sua inauguração, a Rede Globo, cuja concessão no Rio fora outorgada no governo do presidente Juscelino Kubitschek, foi ampliando sua cobertura e, em pouco tempo, entrava no ar em São Paulo, através do Canal 5 (antiga TV Paulista, adquirida do grupo Victor Costa); em Belo Horizonte (pela emissora adquirida do grupo J. B. Amaral em 1968), em Brasília, em 1971 (concessão feita pelo presidente João Goulart em 1962), e em Recife (através de emissora adquirida do grupo Victor Costa), no ano seguinte.

Hoje, a Globo cobre praticamente todo o território nacional, sendo vista por $99,84 \%$ dos 5.043 municípios brasileiros. Os números da Rede Globo são prova definitiva de seu crescimento: 113 emissoras entre geradoras e afiliadas, $74 \%$ de audiência no horário nobre, $56 \%$ no matutino, $59 \%$ no vespertino e $69 \%$ de audiência no horário noturno. No mercado publicitário, a participação da Globo corresponde a $75 \%$ do total de verbas destinadas à mídia televisão. ${ }^{1}$

Das 21 horas diárias no ar (24 horas por dia nos finais de semana), a maior parte da programação é criada e realizada nos estúdios da Rede Globo.

Ela possui um acervo, dublado em diversos idiomas, atingindo espectadores em cerca de 130 países em todos os continentes.

A Rede Globo possui 8 mil funcionários, mobiliza mais de 4 mil profissionais, envolvidos diretamente na criação de seus programas: autores, diretores, atores, jornalistas, cenógrafos, figurinistas, produtores, músicos, além de técnicos nas mais variadas especialidades.

No período de um ano a Globo grava e exibe diversas novelas, miniséries e especiais. Essa produção torna-se mais eloqüente quando computados shows, humorismo, musicais, eventos e jornalismo: são 4.420 horas anuais, algo em torno de 2.210 longas-metragens, o que a coloca na posição de maior produtora de programas próprios de televisão do mundo.

Sucessos de crítica e audiência, as séries brasileiras levaram a Globo a um novo desafio: as miniséries, que nasceram da necessidade de se contar uma história que não poderia ser alongada em muitos capítulos, nem reduzida a apenas um, sem perda de qualidade.

\section{2 - texto de partida: $\bullet$ romance Agosto}

Antes de falarmos sobre a minisérie, resolvemos abordar o romance Agosto, pelo simples motivo de que o produto televisivo serviu-se do romance para construir a minisérie.

Então colocaremos algumas características tanto do autor Rubem Fonseca quanto da sua obra, para ficarmos mais a par deste romance.

Para compreendermos o romance Agosto é necessário saber um pouco do estilo de Rubem Fonseca, que começou a se destacar em 1963, com um pequeno volume de contos intitulado Os Prisioneiros.

$\mathrm{O}$ autor sempre buscou preservar sua 
intimidade, afastando-se de entrevistadores, não comentava suas obras por mais escandalizadoras e criticadas.

Seus romances e contos abordam temas como assassinatos, assaltos, roubos, tráfico de drogas, corrupção policial, violência e sexualidade.

Em Agosto, obra publicada em 1990, o autor segue as suas características primordiais.

De acordo com Gil (1991), seu virtuosismo está quando ele se transforma em narrador de histórias, problematizando uma "verdade" ficcional. Fonseca faz com que exista uma coerência entre o real e a ficção.

Gil (1991) ressalta que o conteúdo e os pressupostos histórico-culturais são fundamentais para dar sentido à composição dos romances de Rubem Fonseca.

Podemos dizer que existe, nos textos de Rubem Fonseca, uma sincronia entre o tempo histórico e o tempo ficcional.

Gil afirma que há uma gradativa inserção do país na esfera do capitalismo industrial de consumo e massa, presente na obra do autor.

No que envolve seus personagens, há sempre uma identificação destes com a realidade social na qual estão inseridos.

Gil (1991: 162) exemplifica esta característica:

"Rubem Fonseca se ordena e toma a direção primeiro no sentido da impossibilidade de os personagens estabelecerem relações substantivas com a realidade social (e as relações pessoais totalmente degradadas ou são vontades e desejos de vivenciar experiências desse mundo que, agora, já se tornaram inacessíveis)."

Além do desmoronamento de todas as relações pessoais entre os seus personagens, o autor os cria em uma esfera antagônica.

Segundo Silva (1980), eles podem ser tanto um burguês quanto um marginal, e também um ser que sofre de um acossa- mento psicológico.

Silva prossegue descrevendo que os personagens ferem e matam, mas sofrem com isto uma eterna angústia, são lúcidos, mas encontram-se sempre desesperados.

Por fim, Rubem Fonseca é caracterizado por ser um escritor bem-dotado e de ter um raro poder de observação do seu meio.

Segundo Afrânio Coutinho (apud Silva 1980), este é um requisito básico para um escritor, para transpor à letra artística mediante o seu imaginário e seu estilo.

"Os livros de Rubem Fonseca são obra de arte literária no melhor sentido, seja pela sua língua vivaz e franca, seja pelo uso de todos os recursos técnicos da arte ficcional moderna, seja pela segura e arguta visão dos costumes sociais contemporâneos." (Coutinho, apud Silva 1980: 168).

Detemo-nos agora em Agosto, que foi publicado em 1990 e caracteriza-se principalmente por se tratar de uma narrativa de cunho policial, de contar com um grande número de personagens que possuem ligações entre si, além do clima de mistério e investigação presente do início ao final da obra.

Para uma maior aproximação com o romance, julgamos imprescindível uma breve sinopse do romance.

A história se resume no assassinato de um empresário ocorrido na madrugada de $1^{\circ}$ de agosto de 1954, no quarto de um luxuoso duplex no Rio de Janeiro. A poucos quilômetros dali, o tenente Gregório Fortunato, chefe da guarda pessoal do presidente Getúlio Vargas, começa a arquitetar outro crime: o atentado ao jornalista Carlos Lacerda, que terminaria 20 dias depois, na maior tragédia política do Brasil.

O personagem central da trama é um delegado de Polícia, chamado Mattos, muito depressivo e incorruptível, atormentado por uma úlcera gástrica e duas namoradas.

Mattos sai obsessivamente atrás de provas, para solucionar os dois crimes - o 
atentado a Carlos Lacerda e o assassinato do empresário - sendo que os dois crimes possuíam um fato em comum: o principal suspeito era um homem negro.

Neste romance podemos identificar alguns pontos levantados por Silva (1980) quando ele caracteriza a obra do autor como a condenação de instituições, a vitória dos bandidos, a violência urbana e o uso de uma linguagem vulgar utilizada, visando a lado trágico das metrópoles, além de servir, para o autor manifestar todo o seu repúdio perante a realidade da qual se ocupa.

Silva continua, destacando que a obra literária de Rubem Fonseca é realista, pois se concentra em temas extraídos de grandes concentrações urbanas e violentas- no caso de Agosto, já que a história se passa no Rio de Janeiro.

Neste romance Rubem Fonseca funde texto e contexto, apresentando um diagnóstico da sociedade em que vive. A trama dos personagens se funde com um momento de grande importância para o Brasil.

É o autor aproveitando-se da realidade, do seu testemunho, transformando-o em uma forma literária. "A literatura não é espelho, escritor não é fotógrafo. Ao invés de reproduzir, sua obra transfigura, revela" (Silva, 1980: 14).

\section{3 - produto final: a minisérie}

A minisssérie Agosto foi realizada pelos cineastas Jorge Furtado e Giba Assis Brasil, baseada no romance Agosto de Rubem Fonseca, para ser veiculada pela Rede Globo.

Segundo Furtado (1992), a tarefa de fazer a adaptação do romance durou sete meses, devido à participação direta de Rubem Fonseca, além de ser a primeira vez que os dois cineastas realizavam um trabalho daquele tipo.

Outro fator que causou uma certa dificuldade foi a falta de delimitação, pois os adaptadores não sabiam quantos capítulos teriam que escrever, ou a duração de cada capítulo.

Já Giba Assis Brasil conta que eles escreveram o roteiro de Agosto entre janeiro e julho de 1992. Porém, a idéia original era que a minisérie fosse ao ar ainda em 1992, o que terminou não acontecendo. Mas a minisérie estreou na Globo dia 24 de agosto de 1993, exatamente 49 anos depois do suicídio de Getúlio Vargas.

A relação dos adaptadores com $\mathrm{Ru}-$ bem Fonseca foi, ao mesmo tempo, intensa, mas sem encontros. De acordo com os cineastas, eles nunca conversaram com o autor, nem pessoalmente, nem por telefone. No entanto, trocaram centenas de páginas a respeito do roteiro, quase sempre através do fax do Carlos Manga, que era o diretor geral do projeto.

Cada capítulo era mandado para a Globo por Sedex e Rubem Fonseca recebia e mandava várias páginas de comentários, sugerindo mudanças ou questionando detalhes. Cabia então ao Jorge Furtado e ao Giba Assis Brasil responderem, aceitando as mudanças ou defendendo o texto deles, conforme o caso. Cada capítulo teve pelo menos três versões completas. O primeiro capítulo, o mais complicado de todos, chegou até a sétima versão, relata Giba Assis Brasil. Foram 16 capítulos, mais de 560 páginas, com nove horas de duração no total.

Jorge Furtado admite que, ao mesmo tempo em que é complicado desenvolver trabalhos na tevê, é um grande desafio, uma vez que tudo será assistido por $40 \mathrm{mi}$ lhões de pessoas simultaneamente. Por isso, o roteiro foi um dos maiores desafios, pois era preciso deixar claro a mensagem que estava sendo passada, sem tornar algo comum e mecânico. Podemos perceber esta dificuldade através deste depoimento de Jorge Furtado, tomando como exemplo uma frase utilizada no roteiro de Agosto.

"Existe uma quantidade enorme de informações quando o personagem diz: 'Tenho que ir até o Catete'. É necessário explicar que o Catete era o paláciosede do governo, que o Rio de Janeiro 
era a capital da República, que Getúlio Vargas morava no Catete. Tudo isso, sem dizer 'vou até a sede do governo, no Catete, onde mora Getúlio', por um simples motivo, as pessoas não falam assim. Parece simples, mas não é. A dosagem de informações tem sempre que pensar nisso: é preciso ser honesto quando se escreve um roteiro." (Furtado, 1992: 47-48)

\section{Um case mal-resolvido: a união do romance com a televisão}

Não podemos negar, num primeiro momento, as diferenças básicas entre o meio pelo qual a mensagem do romance é passada e a da minisérie, mesmo se tratando de um mesmo texto.

Para o jornalista e adaptador Antonio Adami (s.d), adaptar talvez seja pegar as várias leituras do mesmo texto e transformar em uma imagem, que seja,basicamente, o que o autor da obra imaginou. Poderíamos dizer que é um grande exercício de leitura e de reconstrução de sentido de um texto. Adami continua, dizendo que não há fórmula para a reconstrução do texto literário em texto, seja fílmico ou televisivo. $\mathrm{O}$ que marca esta trajetória é a sensibilidade do autor, aquilo que está subjacente, metaforizado na obra de origem. Cabe ao adaptador navegar entre a palavra-imagem.

Sartre (apud Averbuck: 1984) diz que as relações do autor com o universo da tevê significariam um campo novo, um desafio a ser enfrentado seriamente pelo intelectual. Ele destaca que é preciso decifrar a imagem como se decifra um texto, ou seja, encontrar um sentido, significações fornecidas pela imagem. Na televisão, possuímos os dois texto e imagem. Isto requer uma nova leitura, diferente da leitura de imagem fotográfica ou de um romance. É necessário um releitura, pois estamos lidando com um novo texto, onde há uma coexistência destes dois elementos responsáveis pelo dinamismo da televisão.
Walter George Durst (apud Adami, s.d), experiente adaptador e roteirista, lembra que para uma boa adaptação é necessário que seja lido o maior número de obras e informações possíveis sobre o autor, se possível, respirar, inclusive, o mesmo ar do autor, quando este escreveu seu texto de partida - o texto literário.

"Pega-se o tema e tece-se a respeito dele, misturando fidelidade e infidelidade. As variações jazzísticas seriam as variações que se fazem sobre a trama central. $\mathrm{O}$ essencial, apenas, é captar a essência e as nuanças do autor e não fugir do proposto. Resumindo, é fazer um estudo do autor como um todo e manter com ele uma relação de marido e mulher. Numa segunda fase, é conhecer a sua obra e passar a visão do mundo que lá está, manter o original e, a partir daí, criar o que o próprio autor criaria." (Durst apud Averbuck, 1984: 188)

Já para Carlos Saura (apud Adami, 1995), adaptar é, também, demonstrar a cultura e todos os envolvimentos políticos / sociais/econômicos que determinado país passou ou está passando durante a época em que se está produzindo a adaptação.

Adami ressalta que é errado pensar que os textos literários são um roteiro, faltando apenas numerar as cenas. O principal motivo para esta conclusão está nas diferentes linguagens. $\mathrm{O}$ texto televisivo precisa ser seqüencial, linear, apresentar as ações das personagens, além da incursão de elementos sonoros, musicais e imagéticos, imprescindíveis na televisão.

$\mathrm{O}$ autor continua, lembrando que as contradições são que realmente marcam uma narrativa ficcional, são elas as responsáveis em construir o poder dramatúrgico de um texto.

"Adaptar, portanto, é mais do que simplesmente copiar numa outra linguagem, é reconstruir, ou melhor, 
desconstruir um texto, aliás, o 'estupro' é necessário, exatamente pelo respeito às linguagens". (Adami, 1995: 14)

No caso de uma adaptação, Adami acredita ter no mínimo três planos: o da história, o do discurso e o da narração, pois é dentro destes universos do discurso, do conteúdo e da forma de narração do texto de partida que recriamos, construímos e desconstruímos situações, ações, vidas de personagens, espaços. Por isso, acrescenta o autor, é preciso saber manipular a carga ideológica que o texto de partida traz consigo, que é percebida pelo universo imagético-discursivo, que o autor construiu, utilizando, também, o tempo e o espaço como fundamentação da sua história.

O tempo, como foi dito antes, é um elemento essencial na construção da narrativa, seja literária, fílmica ou televisiva. De acordo com Adami, este fator muda todos os caminhos de todas as estruturas de um texto, internas ou externas a ele. $\mathrm{O}$ autor considera o tempo como um agente de muita importância para que se realize uma adaptação de nível, já que é ele o responsável pela melhor compreensão do universo ficcional.

Benedito Nunes, no seu livro Tempo da Narrativa, diz que nas obras literárias ou narrativas o tempo é inseparável do mundo imaginário, projetado, acompanhando o estatuto irreal dos seres, objetos e situações.

Mesmo sendo considerado uma outra obra, a adaptação literária causa diversos incômodos entre os autores literários, que permitiram que as suas obras fossem adaptadas para algum programa televisivo. Lígia Averbuck (1984) diz que muitas vezes os autores sentem-se ressentidos por não reconhecerem a sua obra no vídeo. $\mathrm{O}$ motivo, segundo a autora, é que a sua história não mais o pertence, pois ela está sendo narrada a partir de um outro ponto de vista, relatada por um novo narrador, que alterando o modo de narrar modifica o efeito da obra sobre o leitor.

É importante destacar que a obra lite- rária, de acordo com Averbuck, é um prolongamento do escritor, numa objetivação do que ele tem de mais íntimo e pessoal. No caso da televisão e do cinema, a produção é sempre um trabalho coletivo, em que funcionam todos os elementos da equipe- desde o câmera, até o roteirista e o diretor e onde o autor da adaptação exerce um papel bastante reduzido, se pensarmos no amplo poder de um escritor literário, que comanda a sua ação, suas personagens e linhas narrativas. Por issso muitos escritores resistem aderir a esta forma, pois a tevê faz com que a obra fique restrita a um roteiro e às condições de produção, que envolvem dois elementos muito importantes, dinheiro e tempo para realização, seja de uma minisérie, novela ou filme.

Como as miniséries e as novelas são transmitidas em uma televisão comercial, é sabido que a interferência do espectador possui muito valor. Na medida em que há maior ou menor satisfação de suas expectativas, pode ser alterado o curso da história. A produção faz então crescer uma personagem, do mesmo modo em que anula outra, mudando o desenlace da trama. Ao contrário do filme e do romance, que são entregues ao público acabados, para, posteriormente, serem consumidos.

A questão de autoria da minisérie também é muito discutida, pois no caso do roteiro de televisão, ressalta Averbuck, temos que considerar o "olhar" do diretor de câmera quando este sublinha esta ou aquela cena, ou amplia certa personagem, em especial, sem seguir à risca a descrição feita no roteiro. Ele modifica a leitura no produto final, aquele que será veiculado para o grande público. Sendo assim, a autoria é multiplicada, diluída, através da realização da minisérie.

A televisão é um meio de muitas facetas, ao mesmo tempo ela oferece uma potencialidade multiplicadora da mensagem, além de seduzir o artista com projetos caros, prometendo a democratização do seu trabalho e permitindo-lhe alcançar o grande público. Por outro lado, ela impõe regras, 
condições, códigos e desafios, promovendo, assim, a modificação do produto, alterando a obra como um todo.

Há uma transferência de um gênero para outro. O discurso literário, no momento em que é transformado em discurso televisivo, modifica tanto a organização da obra como o tipo de público que se destina. Segundo Averbuck (1984: 180), "quando os meios são alterados, a mudança se faz em substância: toda mudança formal significa alteração de uma estrutura: portanto do todo".

Exemplos de transformações que a obra literária sofre na televisão podemos citar as declarações de Lígia Fagundes Telles (apud Averbuck 1984), que teve o seu romance Ciranda de Pedra adaptado para a televisão, em 1981. Ela fala que na tevê há os cortes entre os capítulos para se criar um suspense para a entrada do comercial, ou para um "gancho" forte para o capítulo do dia seguinte. Desta maneira o romance torna-se desconhecido ao seu criador. Estas mudanças ocorrem graças à alteração que a imagem causa à palavra.

"O texto se estilhaça em nova configuração: transferindo para o vídeo, o romance televisivionado se alarga e diminui. Seu imaginário e sua densidade se reduzem, enquanto seu público se multiplica várias vezes e seu potencial criativo cresce. Dessa forma satisfaz-se de um lado o sonho do escritor de , pelo lado televisual, projetar o seu recado a milhões de leitores em potenciais, porém na alteração da forma rompe-se, por outro lado, a unidade de sua fórmula, atingindo-se necessariamente o seu conteúdo." (Averbuck 1984: 191)

Por fim, a respeito de adaptações perante a todas as questões levantadas e diferentes pontos de vista, nos permitimos concluir com as palavras de Lígia Fagundes Telles (apud Averbuck 1984: 194), na ocasião em que seu romance Ciranda de Pedra foi adaptado:

“Não participei na adaptação televisiva, nem teve a minha interferência. Acho que foi feita com dignidade, que deu certo. Se reconheço meu romance? Sim e não. Uma coisa é a palavra, outra é a imagem. Mas o adaptador tem de ser respeitado e eu não posso exigir fidelidade ao meu texto."

\section{Fundamentação teórica: a crítica estilística de José Martin}

Este trabalho terá como aporte teórico a crítica estilística de acordo com José Luis Martin (1973), porém com a ressalva que, por se tratar de um ensaio, buscaremos analisar somente os personagens do romance que se repetem na minisérie, em determinada cena.

Será usado especificamente o capítulo XXI, denominado "Caracterização", que está incluso na terceira parte do livro, que trata da investigação estilística, onde o autor mostra uma apresentação pessoal sobre este tema.

Segundo Martin (1973), é importante deixar claro que o estilólogo tem a missão de interpretar para si e para o leitor a obra literária de um autor, estando na mesma situação de um músico intérprete de um compositor. Além disso, Martin acredita que a obra literária é produto do espírito criador do seu autor. Sendo assim, a análise estilística tende a revelar toda a obra criada, em um todo, independente da forma psicológica em que foi criada. Não interessando o processo criador do autor e sim a obra já criada, pronta.

Posteriormente iremos apresentar como está organizado o capítulo, intitulado Caracterização, que iremos estudar. Ele é dividido em três grandes partes: ${ }^{2}$

1-personagens principais e secundários;

2- personagem e ação;

3- ponto de vista, centro de visão o enfo- 
que da caracterização.

\subsection{Personagens principais e secundários}

Martin acredita que, em toda obra literária onde existam personagens, se destaca em um eixo de uma verticalização da mensagem, um objetivo da obra através dos personagens. Na exposição, o autor diz que como na vida as personagens literárias possuem características comuns com a humanidade. Por isso que ocorre uma permanência da mensagem, emitida por elas. Através das personagens há uma humanização de objetos, símbolos, de projeções múltiplas do autor.

"A desumanização da arte não pode dar-se num todo: em todo o humano há humanização. O homem é a medida do universo. O chamado mundo exterior é uma interpretação interior do homem, das vibrações que afetam os seus sentidos e que sua psique interpreta, analisa, valoriza , ama ou odeia." Martin (1973: 248).

É relevante o destaque de Marcos Rey (1989), quando ele diz que mesmo os personagens secundários ou coadjuvantes precisam ser desenhados e cuidadosamente "recheados". Eles precisam viver seus conflitos, possuir uma marca. São eles que permitem a visão de conjunto da obra. "São peças integrantes de um todo, impressão que se perde quando são criados unicamente para contracenarem com o personagem principal" (Rey, 1989: 33).

Retornemos a Martin que, já no Esquema Experimental, faz uma primeira diferenciação envolvendo: personagens principais, secundários e coadjuvantes. Inicialmente relacionando o título da obra com o protagonista, logo em seguida o autor parte do protagonista para levantar o problema deste. Ele no coletivo, ou como terra, deus ou autor. Martin cita, também, a ausência, ou a sugestão do protagonista. No que envolve a relação protagonista e personagem secundário, ele aborda as dificuldades de relações positivas e negativas entre eles.

Um segundo passo do Esquema Experimental, os tipos e as silhuetas são vistos como uma maneira de caracterização local e nacional, símbolos, opinião social, como sombras aos personagens principais, como contrabalanço técnico, ou ainda como uma contrapartida necessária para a psicologia dos personagens. Os tipos também se destacam por trazer com eles um fundamento literário.

Já as silhuetas (esboços, perfis e caricaturas) podem ser recheadas com carga literária, podem ser atribuídas a elas a tarefa de ser um marco técnico da estrutura, ou ainda podem trazer consigo detalhes especiais para os desdobramentos dos personagens. Além destas atribuições, as silhuetas servem como demarcadores ambientais como tempo-espaço, abstração, mundo interior, etc. Sem esquecermos que elas também podem conter motivos poéticos.

Na terceira parte da Exposição, Martin aborda o tema dos personagens símbolos, porém não se estende por tratar em um capítulo específico esta questão.

No quarto item sobre personagens principais e secundários, o autor comenta as diferenças entre personagem individual e personagem universal. O personagem individual possui as seguintes caracaterísticas: é ele e nada mais; pode ser suscetível a outras interpretações; representa uma localidade; costume ou moda; é visto através do humor e da diversão exclusivamente, ou é visto como um simples ser humano sem problemas transcendentais.

O personagem universal pode apresentar uma projeção transcendental do autor, pode ser um símbolo, um motivo humano eterno, uma alegoria local, porém com imanência universal, ou, ainda, tem o objetivo de representar a imortalidade em alguma fase vital do homem.

O último subitem da Exposição Experimental trata da Caracterização, ou seja, é discutido que personagem serve de núcleo 
da obra, que idéia emoção e sensação servem de centro de interesse para os distintos personagens.

As palavras e frases que servem como índice caracterizador para os personagens, que podem se manifestar, através da repetição, a variação, mas com os mesmos moldes, ou o personagem que sempre usa palavras novas ou atrevidas.

A narração, descrição, o diálogo, as sugestões, o monólogo interior e a análise psicológica também são elementos que ajudam a caracterizar os personagens. No entanto, eles também podem não ter nenhuma característica, porém podem ser múltiplos, humanos ou não e podemos contar também com aqueles personagens que são influenciados mutuamente.

Esta primeira análise leva à Discussão (última fase desta primeira análise) de como o autor está desdobrando os seus personagens e que pontos de contato existem entre eles e os tipos.

\subsection{Personagem e Ação}

José Martin, na Exposição, acredita que toda a obra literária necessita que a ação e os personagens estejam intimamente ligados. Pois não faltam personagens para uma ação idealmente estruturada aos objetivos da obra.

No Esquema Experimental, Martin começa descrevendo o personagem único, que, muitas vezes, é o centro, e a história gira ao seu redor; ele pode ser masculino, feminino, fantasmagórico, etc.; pode ser um objeto que represente a obra; outros personagens podem constituir um reflexo, tornando-se único, isto é, vários personagens podem ser representados por um único.

Na segunda parte do Esquema, é tratado a ação interior e exterior. $\mathrm{Na}$ ação interior são considerados aspectos relevantes aqueles ligados ao mundo interior da personagem, os seus reflexos interiores no mundo exterior ou como ele julga essas suas ações. E, por fim, como se dá a relação interior do personagem com o objetivo da obra em um todo.

A ação exterior pode ser compreendida como um reflexo do mundo interior de algum personagem, como uma relação com a psicologia dele, as reações entre os personagens perante a ação exterior. Esta ação também pode causar um controle ou descontrole, estabelecidos pelos personagens. A classificação da ação pode ser vista como: histórica, realista, naturalista, fotográfica, abstrata, irreal, etc.

A terceira parte condiz com a relação do personagem com o ambiente. Pode haver influência do personagem nos fatos, acontecimentos e vice-versa, além de uma espécie de catarse do personagem com o ambiente. Martin questiona se o meio ambiente e a propaganda possuem relação com os personagens, a identificação dele com o regional, e se o personagem usa de uma linguagem própria, pode haver uma relação com o ambiente.

Por outro lado, o meio ambiente pode ser um condicionador do personagem, através do seu criador, seu modificador, destruidor ou a representação de um símbolo.

A quarta parte cita a ação combinada, que é vista como uma ação central com outras subordinadas, ou como várias ações centrais. Também pode aparecer como uma ação dispersa, conexões dos personagens com cada ação. Considera-se, também, os aspectos de fator tempo-espaço, juntamente com os aspectos psicológicos de propaganda.

A última parte se refere aos desdobramentos do personagem, que estão relacionados com o autor, que causa um desenvolvimento psicológico no personagem, a relação com o desenvolvimento dos outros personagens, e os efeitos no objetivo da obra.

A discussão de mais esta parte da análise busca levantar quatro problemáticas que discorrem a respeito da caracterização:

1) a relação entre o protagonista e o autor;

2)o desdobramento do personagem em 
paisagem, e vice-versa, pode ocorrer até que ponto;

3) a ação da projeção natural do personagem principal;

4) o clímax como prova da força de caracterização da obra.

5.3 Ponto de vista, centro de visão e o enfoque da caracterização

Martin inicia afirmando que para se chegar a uma concepção real de unidade de uma criação literária é preciso que nós, leitores, analistas, intérpretes, consigamos ver a obra na sua totalidade e não pelo viés do autor, para, assim, criarmos o nosso particular e pessoal centro de visão.

$\mathrm{Na}$ Exposição Experimental, o autor cita a atmosfera e o tempo na caracterização, que dá condições para levantarmos algumas considerações a respeito desta categoria, tais como: a intensidade da apresentação dos personagens; as preferências de humano e não-humano nos personagens; o personagem-chave da obra, que não precisa ser o protagonista; as ações que acrescentam, destroem ou fazem evoluir o personagem, as preferências para se apresentar o personagem; o tipo de enfoque dado a ele.

O segundo passo do autor é afirmar que a "pessoa" é o personagem que apresenta a ação, porém a discussão repercute através de que mente esta ação ocorre. Uma das alternativas encontra-se na terceira pessoa: o autor pessoalmente, onisciente, observador, onírico, como personagem, etc., outra através da ação geral. $\mathrm{O}$ uso da primeira pessoa pode acontecer por intermédio do protagonista, do personagem secundário, coadjuvante, por um tipo ou silhueta, um objeto, um observador alheio à obra, um personagem fantasma e, por último, pela primeira pessoa do plural.

Não esquecemos de relatar que, na segunda pessoa, se encontra o leitor como narrador e como protagonista e criador.

$\mathrm{Na}$ terceira e última parte da Exposição Experimental, Martin fala das técnicas de apresentação que se manifestam por intermédio de um monólogo interior e exterior, um fluxo de consciência, uma combinação entre personagens, sonho, memória, entre outras formas.

Por fim, José Martin coloca em discussão até que ponto as técnicas de apresentação seguem, embora vão se modificando, gradativamente, e o porquê da necessidade de ter um clímax de maior força na caracterização.

\section{A descrição do objeto}

O nosso objeto de estudo como já foi citado anteriormente será a minisérie Agosto, que se trata de uma adaptação literária. Por este motivo, fizemos todo um apanhado, envolvendo a rede globo, o romance, a minisérie e a fusão dos dois gêneros.

Deve ficar claro que escolhemos analisar os personagens, no caso o comissário Mattos, protagonista da história, e Alice, uma antiga namorada sua, e uma das personagens principais. Para atingir este objetivo será analisada uma determinada cena, com os dois personagens, em que há grande semelhança entre o texto do romance (da página 49 até 51) e o texto utilizado no roteiro $^{3}$, caracterizando assim a nossa finalidade de trabalhar com a adaptação literária.

Esta análise irá seguir os pressupostos de José Martin (1973), de acordo com a seu descrição, feita no seu livro Crítica Estilística, que colocamos na fundamentação teórica.

\section{A metodologia estruturalista}

A Crítica Estilística de José Martin é considerada como um método Estruturalista, pois ela trabalha com a estrutura, com a forma.

Um dos princípios da epistemologia estruturalista segue a premissa de que o Estruturalismo nas Ciências Humanas considera o objeto como um conjunto formado 
por elementos e procura definir as relações entre esses elementos, através de um modelo, acredita Barthes na obra A Análise Estrutural da Narrativa (1971), que foi organizada por ele.

Barthes relata que a noção do Estruturalismo é a da combinatória, ou seja, a partir de um todo dado por segmentações, partições ou substituições, é que conseguimos determinar o nosso elemento e o seu modelo, para posteriormente reconstruirmos teoricamente o todo.

Para Demo (1995: 172), "uma das marcas profundas do Estruturalismo é a acentuação firme de que o conhecimento da realidade se realiza plenamente apenas quando atinge nela elementos constituintes em nível de constantes supratemorais e supra-espaciais." O autor acredita que podemos afirmar que o Estruturalismo explica a variação quando se descobre como ela invariavelmente varia, pois é ao variar constantemente que a explicação torna-se mais profunda.

Retornando ao modelo, Demo o vê como simplificador, já que tenta colocar em um só nucleo a superfície complexa da realidade, ordenando-a , estruturando-a, a fim de encontrar a essência para o fenômeno.

Em suma, o Estruturalismo prega que não é preciso destruir o homem para compreendê-lo, se ao lado da análise colocarmos a síntese.

\section{A análise dos personagens, se- gundo a crítica estilística}

Esperamos ter deixado claro o objeto de nossa análise no item 6 . A partir deste tópico tentaremos caracterizar os personagens de acordo com as premissas descritas por Martin, na sua Crítica Estilística. Trabalharemos com dois personagens, Mattos (representado por José Mayer, na minisérie), um comissário de polícia, honesto, que é atormentado por uma úlcera gástrica e que possui um triângulo amoroso com Alice, uma antiga namorada que surge depois de muitos anos e com Salete (Letícia Sabatella), uma moça pobre que casou por dinheiro, mas vê em Mattos a sua grande paixão. Alice ( Vera Fischer), por sua vez, faz parte da alta sociedade, também é casada, mas possui muitos dramas interiores, é nervosa, e também é apaixonada pelo comissário.

Buscaremos desenvolver a nossa análise seguindo os passos descritos por Martin e levantados na nossa fundamentação teórica.

Iniciamos a caracterização com Personagens principais e secundários. Mattos é o protagonista e pode ser classificado como um personagem, que se assemelha à pessoa, ou seja, é humano, possui tristezas, inseguranças, alegrias, decepções, etc.

Alice representa uma personagem que mostra o passado de Mattos, mostrando para o leitor um pouco do seu lado interior, ao citar assuntos de sua juventude. Ela tem características de um mulher frágil que necessita ajuda, podemos considerá-la como o "sexo frágil".

O tipo de Mattos inspira uma caracterização da época em que se passa o romance, durante o período Vargas. Ele é responsável por mostrar a cultura da época, demarcar o tempo da narrativa, além de ser o responsável por ligar as outras tramas do romance. Já o tipo de Alice espelha uma opinião social, onde a mulher não tinha independência e só seria realmente feliz se tivesse um homem ao seu lado para resolver seus problemas.

Mattos é classificado com um personagem- indivíduo, é suscetível a diversas interpretações. Sua presença pode ser vista por diversos ângulos, de acordo com a situação que o personagem está passando. Alice é ela e nada mais, porém serve como uma representação da moda e costumes dos anos 50, especificamente da sociedade carioca.

A caracterização de Mattos pode ser confirmada por ele servir de núcleo da obra, fazendo os personagens principais e 
coadjuvantes girarem em torno dele, por ser o centro de interesse da história. Uma de suas características é quando perante a uma situação embaraçosa, como no encontro com Alice, na cena em que escolhemos, ele busca, através de um monólogo interior, explicações e respostas para o acontecimento que está ocorrendo. Alice pode ser caracterizada como um ser sentimental, por lidar mais com as emoções, através dos seus diálogos cheio de sugestões.

Seguindo o segundo passo de Martin, denominado Personagem e Ação, vemos que o comissário Mattos possui uma estreita ligação psicológica com o autor. Muitas vezes o autor parece falar por intermédio do pensamento do personagem. Há uma ação interior no personagem, pois ele reflete os elementos do mundo exterior, além de refletir a estrutura da obra. Já a sua ação exterior ele reflete o mundo interior de Alice e controla, modifica a ação externa dos outros personagens.

Alice pode ser vista como um espelho dos sentimentos de Mattos, que guarda uma mágoa muito grande a seu respeito. Ela pratica ações interiores, mostrando, também, o lado interior do comissário.

A relação de Mattos com o ambiente se dá através dos acontecimentos, que causam modificações no comportamento de Mattos, que o faz se projetar e se desenvolver no desenrolar da trama. Já Alice se relaciona com os modismos e com o local.

A ação combinada do protagonista com os outros personagens ocorre por participar de ações centrais. Assim, vai acontecendo o seu desdobramento, afetando o clímax do romance. Então, a ação causa uma projeção natural do personagem que tem a finalidade de caracterizar a obra. Alice concebe a ação combinada, quando junta Salete (amante de Mattos), Mattos e ela, cruzando os pontos da narrativa. Porém na cena analisada, ela passa fatores humanísticos nas suas ações, além de manter uma relação direta com o protagonista.

O último aspecto, levantado por Martin, é o Ponto de vista, Centro de Visão e Enfo- que de Caracterização, que vem caracterizar a obra através do seu todo, e não somente sob a ótica do autor. $O$ personagem incluso no ambiente e no tempo é muito importante para a caracterização, isto é, há ações, feitas por Mattos, que acrescentam, destroem ou fazem evoluir os outros personagens. $\mathrm{O}$ autor prefere o diálogo para a apresentação de Mattos, porém o monólogo e a descrição, também, colaboram para compreendermos mais o personagem, que apresenta enfoques: psicológico, social e temático.

Alice caracteriza a atmosfera do romance através do seu enfoque lírico, com seus diálogos e monólogos. Sua personagem se apresenta tanto pelo autor como pelo protagonista. Enquanto o responsável pela apresentação da ação de Mattos fica por conta do autor, às vezes, pessoalmente, outras como observador ou ainda como personagem.

\section{- 0 personagem unindo liferatura e imagem}

Após um exaustivo trabalho até chegarmos aos personagens, que na opinião de diversos autores são a alma das histórias, percebemos que a sua relevância, através da sua caracterização, é a responsável pelo sucesso e identidade da obra. A partir das suas características é desenvolvida a narrativa e são demarcados o espaço e o tempo.

Pelo menos neste aspecto tanto os autores televisivos quanto os autores literários concordam. Não importa se a obra é realizada por um ou por uma equipe, os personagens devem ser construídos e representados partindo de uma caracterização forte que o coloquem em sintonia com o objetivo da obra.

Por isso, esta discussão a respeito das adaptações literárias perde a sua força quando pensamos nos personagens em si. O que muda é o veículo, sempre haverá lugar para todos os gêneros. Cada um com seu charme e atrativos. Mais uma vez encerraremos com a citação da escritora lígia 
Fagundes Telles, quando acusam a TV de não ser um formador cultural, além de desviar a leitura: "a televisão não tira os leitores. quem tira os leitores é a vida. E a vida no Brasil virou artigo de luxo" (apud Averbuck, 1984: 202)

\section{Anex॰}

Abaixo está a transcrição de um trecho do roteiro de Agosto, exatamente a cena em que o Mattos e a Alice se encontram na confeitaria Cavé. ${ }^{4}$

\section{CENA 2-19 INT/NOITE - CONFEITARIA CAVÉ}

Mattos está sentado a uma mesa da confeitaria. A decoração é a mesma de sete anos atrás. Alice se aproxima. Mattos se levanta, puxa uma cadeira para ela sentar. Os dois sentam e ficam alguns segundos sem falar. Alice abre a bolsa, tira um maço de cigarros e um isqueiro e coloca sobre a mesa.

ALICE:

- Eu agora estou fumando.

Mattos pega 0 isqueiro e acende o cigarro dela. 0 garçom se aproxima. Mattos olha para o garçom, depois para Alice. Alice fuma. Alguns segundos de silêncio constrangedor.

MATTOS (para Alice):

- Chá?

ALICE:

- Com torradas.

MATTOS (para o graçon):

- Dois.

O garçom anota o pedido e sai.

ALICE:

- Você ainda está no departamento?

MATTOS (percebendo o ato falho):

- Estou (pausa).

- O Seu Emílio me ligou hoje. Lembra dele?

ALICE

- Não.
MATTOS:

- 0 velho, chefe da claque do Teatro Municipal. Lembra? 0

Seu Emílio... Acho que vou encontrá-lo, amanhã ou depois.

ALICE:

- Lembro que você falou que tinha trabalhado na claque. Antes de...antes de me conhecer.

O garçom chega com o chá. Alice apaga o cigarro.

MATTOS:

- Não vejo o Seu Emílio há muito tempo. Na última vez, matei aula pra me encontrar com ele em frente à estátua do Chopin. Era ali que a gente se reunia. Naquele dia íamos combinar a claque do "Parsifal".

Mattos toma um gole de chá, não sabe o que dizer. Alice também não. Mattos continua falando sobre ópera, só para não deixar o silêncio crescer muito.

MATTOS:

- As óperas de Wagner eram as que davam mais trabalho para o pessoal da claque. Em "Parsifal" sempre tem alguém que quer aplaudir no final do primeiro ato. A gente tinha que fazer o público ficar quieto. Isso era o mais difícil. Fazer o público aplaudir era fácil.

Pausa.

ALICE:

- Vi o Parsifal em... (constrangida) em Londres. Não lembro se eu aplaudi no final do primeiro ato.

Pausa.

MATTOS:

- Eu não cheguei a ver. Acabou não sendo encenada. (pausa) A claque foi dissolvida logo depois. Acabou, saiu de moda.

Alice pega outro cigarro, Mattos acende.

ALICE:

- Você tem ido ao Municipal?

MATTOS (fazendo não com a cabeça):

- Ópera não me interessa mais...

Mattos pega a faca e fica lendo a palavra INOX gravada na 
lâmina. Alice olha para a asa da xícara à sua frente. Cada um evita olhar diretamente para 0 outro.

ALICE:

- Minha mãe morreu.

MATTOS:

- Sinto muito.

ALICE:

- Por quê? Ela não gostava de você.

Mattos lê a palavra INOX na faca.

ALICE:

- Eu me casei.

MATTOS:

- Eu sei.

ALICE:

- O Pedro é uma boa pessoa (pausa). Sabe a nosso respeito.

MATTOS:

- Sabe o quê? Não há nada para saber.

ALICE:

- Sabe que não há nada para saber (pausa). E você? Casou?

MATTOS:

- Não.

Os olhares se cruzam por instantes.

MATTOS:

- Não vai me dizer o que queria comigo?

\section{ALICE:}

- Acho que vou deixar para outro dia... Não estou sabendo dizer o que... o que eu queria dizer (pausa). Você se encontra comigo outra vez? Quarta-feira? Talvez quarta-feira eu tenha mais coragem.

\section{MATTOS:}

- Quarta, não posso. Meu plantão começa ao meio-dia. Saio na quinta, meio-dia.

ALICE:

- Então quinta.
Mattos concorda com a cabeça. Depois faz um sinal, chamando 0 garçom.

(FINAL DA CENA)

\section{Notas}

1 Dados retirados do site wwww.redeglobo.com.br

2 Todas estas partes se organizam em: a) Exposição, b) Esquema Experimental e c) Discussão.

3 Tanto o texto do romance quanto a parte do roteiro referentes a esta cena estão disponíveis nos anexos 1 e 2.

40 texto foi adquirido, via e-mail, com um dos adaptadores, o Giba Assis Brasil.

\section{Referências}

ADAMI, Antônio. $O$ Espectador do Cinema e o Poder Dramático dos textos Adaptados à Linguagem Audiovisual. (mimeo). Texto apresentado no Compós, s.d.

AVERBUCK, Lígia (org). Literatura em tempo de Cultura de Massa. Editora Nobel, São Paulo, 1984.

DEMO, Pedro. Metodologia Científica em Ciências Sociais. Editora Atlas, São Paulo, 1995.

FIELD, Syd. Manual do Roteiro: fundamentos do texto cinematográfico. Editora Objetiva, Rio de Janeiro, 1979.

FONSECA, Rubem. Agosto. Editora Schwarcz Ltda, São Pau10, 1991.

FURTADO, Jorge. Um Astronauta no Chipre. Artes\&Ofícios, Porto Alegre, 1992.

GIL, Fernando Cerisara. "A poética da destrutividade: texto e contexto em Rubem Fonseca". Dissertação de Mestrado, do Pós-Graduação de Letras da UFRGS, 1991.

MARTIN, José Luis. Crítica Estilística. Editorial Gredos, Madrid, 1973.

NUNES, Benedito. O Tempo da Narrativa. Editora Ática, São 
Paulo, 1995.

REY, Marcos. O Roteirista Profissional. Editora Ática, São Paulo, 1989.

SCHÜLER, Donaldo. Teoria do Romance. Editora Ática, São Paulo, 1989.

SILVA, Deonísio da. "O palimpsesto de Rubem Fonseca: violência e erotismo em Feliz Ano Novo". Dissertação de Mestrado, do curso de Pós-Graduação de Letras da UFRGS, 1980. 